Article

\title{
Evaluation of Surface Integrity in 18CrNiMo7-6 Steel after Multiple Abrasive Waterjet Peening Process
}

\author{
Yun Zou, Yafeng Xu, Jingkai Li, Shuhao Liu, Dong Wang and Yang Li * \\ School of Mechanical and Power Engineering, Zhengzhou University; Zhengzhou 450001, China; \\ yunzou@zzu.edu.cn (Y.Z.); zzuxuyafeng@163.com (Y.X.); likaizzu@163.com (J.L.); shuhaoliuzzu@163.com (S.L.); \\ wangdong@zzu.edu.cn (D.W.) \\ * Correspondence: yangli@zzu.edu.cn; Tel.:+86-371-67781235
}

Received: 6 June 2020; Accepted: 24 June 2020; Published: 26 June 2020

\begin{abstract}
Abrasive waterjet peening (AWJP) as an important surface strengthening method can effectively improve surface properties. In this study, after multiple AWJP, the distribution of compressive residual stress and roughness on the surface of 18CrNiMo7-6 steel has been evaluated by an X-ray diffraction (XRD) method and a 3D surface topography system, respectively. Compared with the single AWJP, multiple AWJP can obviously increase the surface residual stresses (-1024 MPa to $-1455 \mathrm{MPa})$ and the depth of maximum compressive residual stress (100 $\mu \mathrm{m}$ to $120 \mu \mathrm{m})$, as well as make the stress distribution more uniform. In terms of the surface roughness, multiple AWJP influences its uniform distribution and reduces the surface roughness $\left(\mathbf{S}_{\mathbf{a}}=0.69 \mu \mathrm{m}\right)$, compared with a single AWJP $\left(\mathbf{S}_{\mathbf{a}}=2.96 \mu \mathrm{m}\right)$, due to the smaller shot balls and a uniform deformation during multiple AWJP. In addition, we have studied the effects of multiple AWJP on the hardness of the surface layer. The results show that multiple AWJP increases the hardness by up to $15.9 \%$, compared to the single AWJP. These studies provide useful insight into improving the surface properties of 18CrNiMo7-6 steel by multiple AWJP.
\end{abstract}

Keywords: abrasive waterjet peening; residual stress; hardness; surface roughness

\section{Introduction}

The study of mechanical properties of metals and alloys, including steel, and their resistance to external factors, is a fundamental matter for the development of multiple technological applications [1,2]. $18 \mathrm{CrNiMo} 7-6$ steel is widely used in the field of transportation, energy generation and general mechanical engineering, such as bearings, gears and wear pins, due to its three key characteristics: high wear resistance; good fatigue strength; and cost efficiency [3]. However, during the manufacturing processes such as cutting and grinding, tensile stresses always generate, which will deteriorate the fatigue life. In order to improve the fatigue life of industrial components, the residual stresses in the surface layer must be suppressed [4]. In addition, key components require hard surface layers and good surface quality. Surface deformation strengthening methods, such as shot peening (SP) [5,6], laser shot peening (LSP) $[7,8]$, surface mechanical grinding treatment (SMGT) $[9,10]$ and surface mechanical attrition treatment (SMAT) [11,12] can generate a beneficial microstructure and compressive residual stress to induce property enhancements. The surface deformation strengthening technology means to make the surface produce a certain degree of plastic deformation led to the forming of a certain depth of the deformation layer, which can improve the material properties [13].

Abrasive waterjet peening (AWJP) is a metal strengthening technology based on a basic principle like shot peening (SP), but it shoots balls along with high-pressure and high-speed water rather than air. During the process of AWJP, a large number of small balls with high kinetic energy impact on the metal surface, which causes a large elastic and plastic deformation [14,15]. The residual compressive 
stress is introduced together with the plastic deformation in surface layers, which improves the surface properties of the treated components. Since the AWJP has more kinetic energy than traditional SP, the strengthening effect of AWJP is better. Arola et al. [16] studied the influence of AWJP on the compressive residual stress, surface texture and fatigue strength of a stainless steel and titanium alloy. The results showed that the compressive residual stress is primarily influenced by the abrasive size and treatment pressure, however the surface roughness increases. Arola et al. [17] also found that the residual stresses resulting from AWJP decreased with an increase in both jet pressure and abrasive size. Fu and Liang [14] used AWJP to process AISI 4340 steel, and the results showed that the surface modification can produce a deep deformation layer but a worse surface condition. In order to improve the surface quality, they used ultrasonic surface rolling to modify the rough surface.

As mentioned above, AWJP not only takes in a serve surface deformation, but also deteriorates the surface quality [18]. In order to improve the surface quality of the samples treated by AWJP, we learn from the multiple SP methods [19-22] and study the effect of multiple AWJP on the surface integrity of 18CrNiMo7-6 steel. SP can be carried out in several steps, such as single, dual and triple SP. In the multiple SP, the second or third step is always peened at a lower intensity than the first step for improving the surface integrity. Moreover, the uniformity of residual stress is an important parameter for evaluating the fatigue strength, as uneven residual stress distribution on the surface can deteriorate the surface property of the component [23].

In this work, after the single, dual and triple AWJP, the distribution of surface residual stress and sub-surface residual stress will be measured by an X-ray diffraction (XRD) method. Furthermore, the surface roughness of $18 \mathrm{CrNiMo} 7-6$ steel will be measured by a 3D surface topography system, and then the uniformity of distribution will be discussed in detail. In addition, the hardness related to multiple AWJP will be researched and discussed. Therefore, this work focuses on how to improve the surface uniformity of 18CrNiMo7-6 steel by multiple AWJP.

\section{Experimental Methods}

\subsection{Materials}

The studied samples are manufactured from case-hardened steel 18CrNiMo7-6 (EN 10084). The chemical composition of $18 \mathrm{CrNiMo7-6}$ steel is summarized in Table 1. All the samples are carburized at $920^{\circ} \mathrm{C}$ for $34 \mathrm{~h}$ in a controllable gas carburizing furnace, then subsequently quenched at $820^{\circ} \mathrm{C}$ in oil to room temperature, then followed by tempering at $180{ }^{\circ} \mathrm{C}$ for $3 \mathrm{~h}$, and finally cooling in air. Samples with a dimension of $20 \times 20 \times 20 \mathrm{~mm}$ are cut via the wire electrode cutting method, and ground to 800 -grit $\mathrm{SiC}$ prior to being subjected to the AWJP process.

Table 1. Chemical Composition of 18CrNiMo7-6 Steel.

\begin{tabular}{ccccccccc}
\hline $\mathbf{C}$ & $\mathbf{S i}$ & $\mathbf{M n}$ & $\mathbf{S}$ & $\mathbf{P}$ & $\mathbf{C r}$ & $\mathbf{N i}$ & $\mathbf{M o}$ & $\mathbf{F e}$ \\
\hline 0.18 & 0.4 & 0.60 & $\leq 0.035$ & $\leq 0.035$ & 1.70 & 1.60 & 0.30 & bal \\
\hline
\end{tabular}

\subsection{AWJP Processes}

The AWJP experiments are carried out on a waterjet machine (OMAX corporation, Kent, WA, USA), which can generate water pressure from $5 \mathrm{MPa}$ to $430 \mathrm{MPa}$. The experimental setup and schematic diagram of the AWJP process are shown in Figure 1. The nozzle used in this experiment is a round one with a diameter of $2.0 \mathrm{~mm}$, and the moving speed and feed of the nozzle are $500 \mathrm{~mm} / \mathrm{min}$ and $0.25 \mathrm{~mm}$, respectively. The incidence angle and standoff distance between the nozzle and the samples are set at $90^{\circ}$ and $10 \mathrm{~mm}$, respectively. The detailed parameters of AWJP progress are shown in Table 2. In this experiment, the abrasive media are two kinds of shot balls, cast steel balls with a hardness of HRC45-50 and ceramic balls with a hardness of HRC50-55. Media materials are commonly used in traditional shot peening. The detailed parameters of multiple AWJP are shown in Table 3. For 
example, the sample 'S4' was first AWJP processed by cast steel balls ( $0.2 \mathrm{~mm}$ round) with a water pressure of $300 \mathrm{MPa}$, and then the second AWJP process was performed by ceramic balls $(0.1 \mathrm{~mm}$ round) with a water pressure of $200 \mathrm{MPa}$. Since sample S4 is treated by AWJP twice, the peening time is twice as much as a single AWJP. In the AWJP process, a large amount of water, followed by many balls, beat on the surface of samples with high kinetic energy. Obviously, the kinetic energy was related to the parameters of the AWJP process, and the water pressure is the most important parameter, which can be found in our previous work [24]. After the AWJP process, we selected the center area with $10 \times 10 \mathrm{~mm}^{2}$ to measure the surface properties. Moreover, a corresponding sample was prepared for comparison.

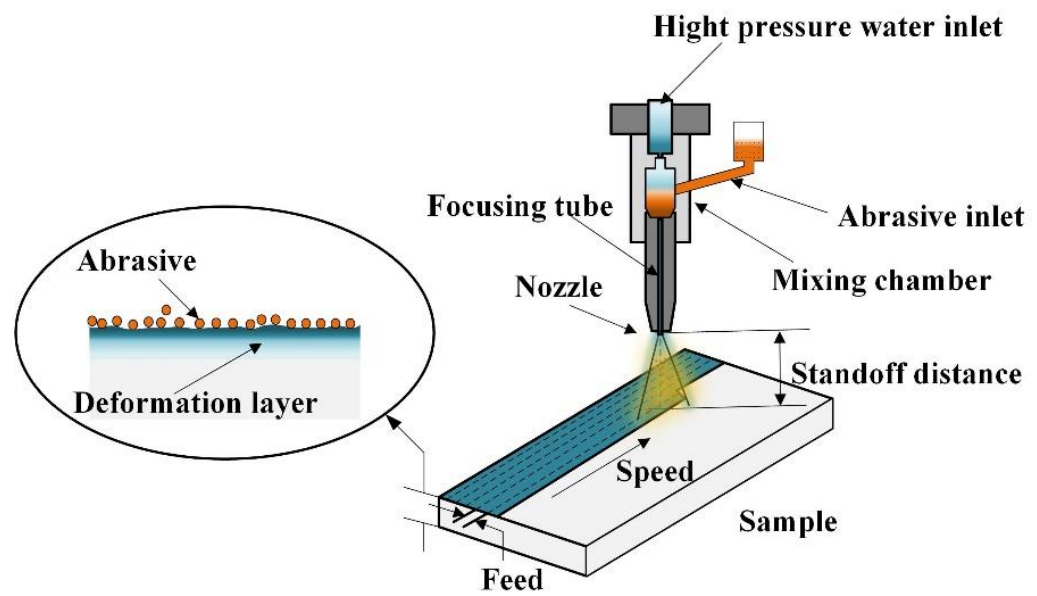

Figure 1. The schematic diagram of abrasive waterjet peening (AWJP).

Table 2. Parameters of AWJP progress.

\begin{tabular}{cc}
\hline Parameters & Values \\
\hline Water pressure $(\mathrm{MPa})$ & 5 to 430 \\
Nozzle diameter $(\mathrm{mm})$ & 2.0 \\
Moving speed $(\mathrm{mm} / \mathrm{min})$ & 500 \\
Feed $(\mathrm{mm})$ & 0.25 \\
Incidence angle $\left({ }^{\circ}\right)$ & 90 \\
Standoff distance $(\mathrm{mm})$ & 10 \\
\hline
\end{tabular}

Table 3. Detailed parameters of multiple AWJP processes.

\begin{tabular}{cccccc}
\hline AWJP Method & Sample & Media Materials & Pressure (MPa) & $\begin{array}{c}\text { Diameter of } \\
\text { Balls }(\mathbf{m m})\end{array}$ & $\begin{array}{c}\text { Peening Time } \\
(\mathbf{m i n})\end{array}$ \\
\hline $\begin{array}{c}\text { Corresponding } \\
\text { sample }\end{array}$ & S0 & none & none & none & none \\
Single AWJP & S1 & Ceramic & 200 & 0.1 & 3.2 \\
Single AWJP & S2 & Cast steel & 200 & 0.2 & 3.2 \\
Single AWJP & S3 & Cast steel & 300 & 0.2 & 6.2 \\
Dual AWJP & S4 & Cast steel + ceramic & $300+200$ & $0.2+0.1$ \\
Triple AWJP & S5 & Cast steel + cast steel + ceramic & $300+200+200$ & $0.2+0.2+0.1$ \\
\hline
\end{tabular}

\subsection{Residual Stresses and Microstructure Measurements}

The XRD analysis was obtained via XRD equipment (Empyrean, PANalytical, Almelo, The Netherlands) using Cu-Ka radiation $(\lambda=1.54056 \dot{\mathrm{A}})$. The generator settings were $40 \mathrm{kV}$ and $30 \mathrm{~mA}$, the diffraction data were collected over a $2 \theta$ range of $30-90^{\circ}$, with a step width of $0.02^{\circ}$ and a scan speed of $2^{\circ}$ per minute.

The magnitude of the induced residual compressive stress of the samples was measured by an X-ray residual stress analyzer (LXRD; PROTO, Oldcastle, ON, Canada) with Cr K $\alpha$ radiation (Ni filter), 
and the XRD system was calibrated by a stress-free sample. The residual stress tests were conducted according to ASTM: E915-10. The voltage and current were $30 \mathrm{kV}$ and $25 \mathrm{~mA}$, respectively. The $\mathrm{Cr}$ $\mathrm{K} \alpha$ radiation with a wavelength $\lambda=2.2897 \dot{\mathrm{A}}$ was used to determine the ferrite (211) diffraction peak. The residual stress was determined by the $\sin ^{2} \psi$ method [25]. An average of at least five residual compressive stresses data was recorded. The in-depth profiles of residual stresses were received by removing the surface layers one-by-one via chemical etching with the saturated salt solution.

Moreover, the hardness was measured by a Micro-hardness Tester (HV-1000, Beijing Times Mountain Peak Technology, Beijing, China) with a force of $1.96 \mathrm{~N}$ and a loading time of $15 \mathrm{~s}$. In order to obtain the hardness distribution at different depths, the surface layers were removed one-by-one via chemical etching with the saturated salt solution. An average of at least five hardness data was recorded at every depth.

The surface state of the samples was measured by NPFLE 3D surface topography system (Bruker Nano Inc, Karlsruhe, Germany). A measurement area of about $1500 \times 1500 \mu \mathrm{m}^{2}$ was covered. Light and dark colors indicated peak and valley regions, respectively. An average of at least five roughness values was used for evaluating the surface roughness $\left(\mathbf{S}_{\mathbf{a}}\right)$. All the experiments were conducted at room temperature.

To reveal the subsurface microstructure, the cross-sections of the samples were metallographically ground and polished, followed by etching with $4 \%$ Nital. The microstructures of the samples were subsequently observed by scanning electron microscopy (Zeiss Auriga FIB-SEM, Jena, Germany).

\section{Results and Discussion}

\subsection{Residual Stress Analyses}

In Figure 2, the depth profiles of residual stress for all the surface treated samples are displayed. As shown, since the samples have been heat-treated before AWJP, compressive residual stress occurred in the near surface region of the corresponding sample S0. However, the maximum compressive stress $(-267 \mathrm{MPa})$ and the depth of compressive region $(40 \mu \mathrm{m})$ are limited. After single AWJP treatment, the maximum compressive stress of the $S 1$ sample is $-1280 \mathrm{MPa}$ and the depth of the compressive region is $250 \mu \mathrm{m}$, which were introduced by the ceramic balls peening with a water pressure of $200 \mathrm{MPa}$. With the increasing of depth, the compressive residual stress (CRS) increases, firstly to the maximum at $65 \mu \mathrm{m}$, but then declines rapidly along the layer depths, and finally approaches zero. In comparison, if the single AWJP process was conducted by cast steel balls (0.2 mm round) with a pressure of $200 \mathrm{MPa}$, the maximum CRS and the depth of the compressive region of S2 sample are $-1180 \mathrm{MPa}$ and $760 \mu \mathrm{m}$, respectively. Since the steel balls are bigger and heavier, and are prone to cause higher kinetic energy than the ceramic balls, the influence depth is greater. However, the ceramic balls have high hardness and poor plasticity, so the maximum CRS is bigger than that caused by the steel balls.

If we increase the water pressure of the single AWJP process to $300 \mathrm{MPa}$ by the same cast steel balls, the maximum CRS and the depth of compressive region of the S3 sample are $-1191 \mathrm{MPa}$ and $760 \mu \mathrm{m}$, respectively. This is an expected trend, since the higher water pressure makes the steel balls own the higher energy, and more serious plastic deformation is produced on the surface layer. We can find the similar results in SP treatment. For example, Mohamed et al. [26] observed that the applied air pressure has the largest effect on the shot peening process when compared to other process parameters, where high air pressure induces a thick and uniform compressed surface layer, compared to low pressure. 


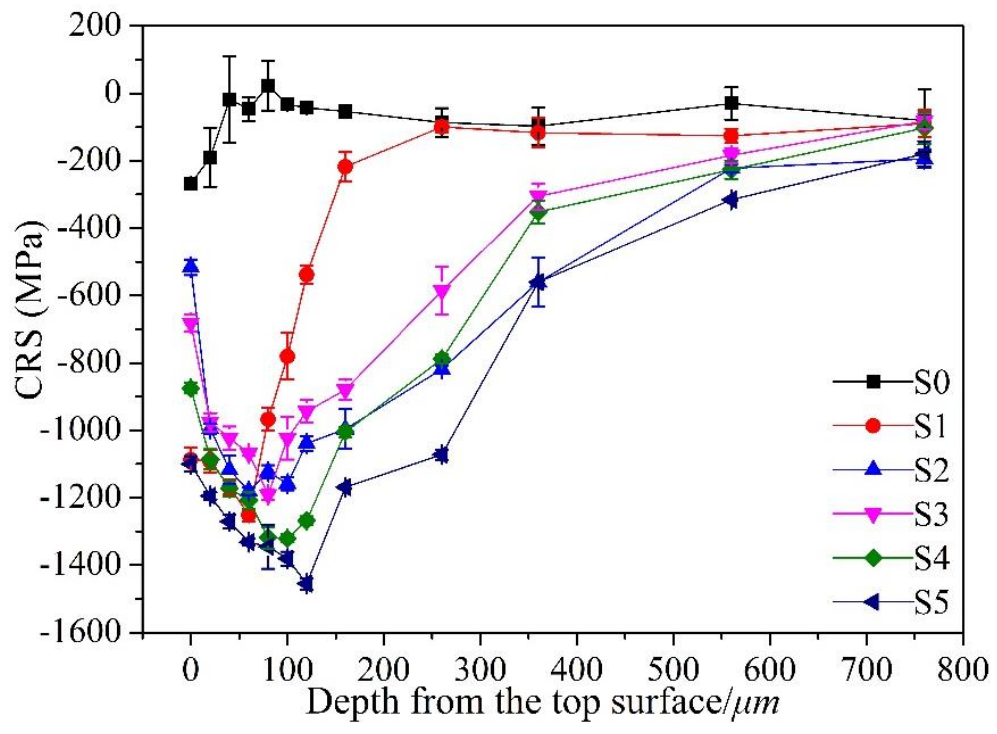

Figure 2. Depth profiles of the residual stress.

As depicted in Figure 2, the dual AWJP induces a higher CRS than single AWJP in the upper layer of the sample S4. The maximum CRS increases from -1191 MPa to -1321 MPa, although the depth of the compressive region sees no change. This is to be expected, as since the ceramic balls are prone to cause near-surface deformation, the influence depth is limited. After the sample was treated by the first AWJP treatments with the pressure of $300 \mathrm{MPa}$, the depth of compressive region is $760 \mu \mathrm{m}$, so the ceramic balls with low kinetic energy struggle to cause large deformation on the thick hardened layer [19], and just increase the surface compressive stress.

In order to get a high value of compressive residual stress, sample S5 was processed by triple AWJP. The maximum CRS of the sample S5 increases from -1191 MPa to $-1455 \mathrm{MPa}$, and the depth of compressive region of the sample S5 sees almost no change, compared with the sample S3 treated by single AWJP. As can be seen in Figure 2, the surface CRS and maximum CRS of samples S4 and S5 increase compared to the sample S3, after the multiple AWJP processes. However, the depth of compressive region of samples S4 and S5 see almost no change. In the multiple AWJP process, the samples were fully peened at a higher intensity, and then re-peened in a second or third operation at a lower intensity. Therefore, the depth of the compressive region depends on the first step of the multiple AWJP, and it is almost same for samples S3, S4 and S5.

Figure 3 shows the distribution of residual stress on the surface of the sample S3, and the related parameters are displayed in Table 4 . As we all know, the standard deviation can reflect the uniform, the smaller standard deviation, the more uniform of the residual stress of distribution. It can be found that the sample S3, which was treated by the steel balls peening with a water pressure of $300 \mathrm{MPa}$, has the highest standard deviation (63.26), so its distribution of residual stress is the most non-uniform.

We use a ratio (R) introduced by Xie et al. [19] to define the uniformity of residual stress distribution, where $\mathrm{R}$ is the ratio of the average residual stress to the standard deviation. It can be found in Table 4 that the ratio of sample S1 is highest (50.41), which means that the single AWJP with ceramic balls produces the most uniform distribution of residual stress. If we process the sample with ceramic balls after the first or second step of the AWJP, the distribution of residual stress will be more uniform compared with the single AWJP. The experimental results of S4 and S5 have verified the validity of multiple AWJP in improving the uniformity of residual stress distribution. Through Kobayashi's research [27], shot peening creates an almost uniform compressive residual stress distribution along a surface after many small steel balls collided with the surface, due to the superposition of residual stress produced by surrounding shots. Therefore, the distribution of the residual stress of the sample treated by multiple AWJP is more uniform than that treated by a single AWJP. Moreover, the uniformity of stress distribution is very important for the component's fatigue resistance. 


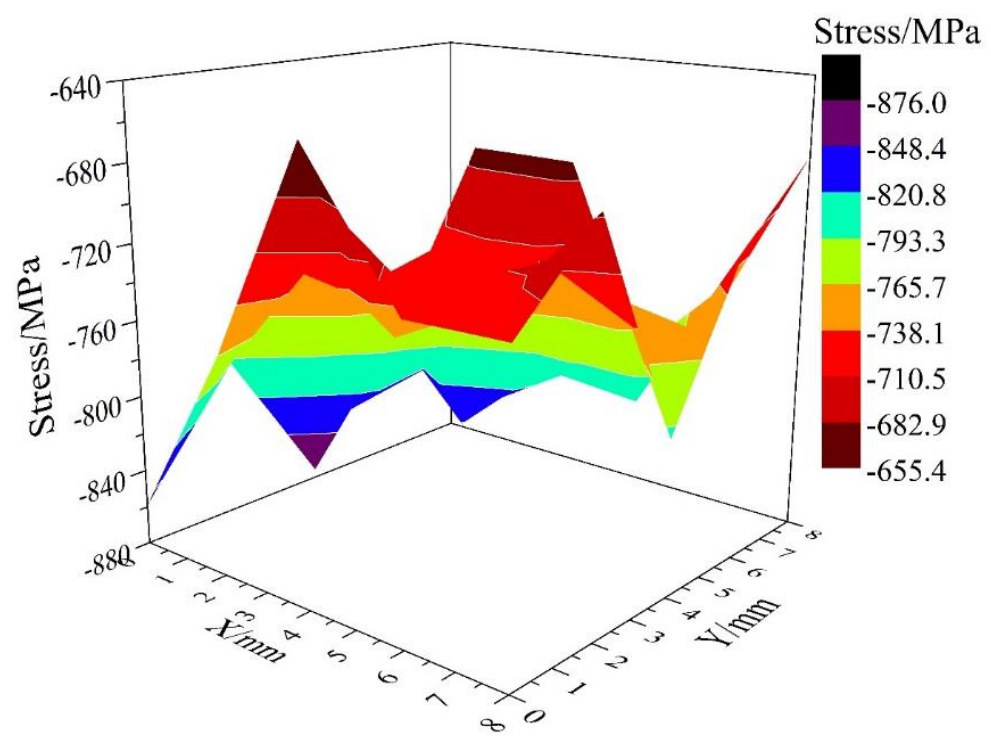

Figure 3. Residual stress distribution on the surface of Sample S3 after AWJP treatments.

Table 4. Distribution of surface residual stress of $18 \mathrm{CrNiMo7-6}$ steel after AWJP treatments.

\begin{tabular}{ccccc}
\hline Sample & $\begin{array}{c}\text { Range of Residual } \\
\text { Stress/MPa }\end{array}$ & $\begin{array}{c}\text { Average of } \\
\text { Residual } \\
\text { Stress/MPa }\end{array}$ & $\begin{array}{c}\text { Standard } \\
\text { Deviation } \\
\text { Values/MPa }\end{array}$ & R \\
\hline S0 & $-380.79 \sim-420.17$ & -410.79 & 17.60 & 23.33 \\
S1 & $-976.94 \sim-1053.4$ & -1019.89 & 20.22 & 50.41 \\
S2 & $-443.31 \sim-531.21$ & -498.78 & 27.02 & 18.13 \\
S3 & $-655.35 \sim-875.27$ & -765.65 & 63.26 & 12.10 \\
S4 & $-604.14 \sim-659.22$ & -634.96 & 17.05 & 37.24 \\
S5 & $-1020.99 \sim-1119.77$ & -1064.98 & 22.05 & 48.30 \\
\hline
\end{tabular}

Figure 4 shows the XRD patterns of the top surface of $18 \mathrm{CrNiMo7-6}$ steel before and after AWJP treatments. As depicted in Figure 4, both martensite $(\alpha)$ and austenite $(\gamma)$ phases are found in the top surface of $18 \mathrm{CrNiMo7}-6$ steel before AWJP treatment. A small amount of austenite is still retained after sample S2 is treated by AWJP treatments by cast steel balls $(0.2 \mathrm{~mm}$ round) with a pressure of $200 \mathrm{MPa}$. However, only martensite state is tested after triple AWJP treatment, implying that the retained austenite has transformed to the martensite state by multiple AWJP treatments. AWJP treatments can improve the mechanical properties of the surface of $18 \mathrm{CrNiMo} 7-6$ steel, as the retained austenite contents decrease near the surface region. These similar results could be found in SP treatments $[5,21]$.

\subsection{Surface Morphology and Roughness}

Figure 5 shows the 3D surface topographies of samples treated under different AWJP processes, and the values of $\mathbf{S}_{\mathbf{a}}$ are displayed in Table $5 . \mathbf{S}_{\mathbf{a}}$ is a commonly used parameter for the evaluation of measured surface roughness, which denotes the arithmetical mean height. Figure $5 \mathrm{a}$ is a polished sample's surface morphology, the surface has the texture left by the polishing process, and the sample $\mathrm{S} 0$ has a $\mathbf{S}_{\mathbf{a}}$ value of $0.19 \mu \mathrm{m}$. The value of $\mathbf{S}_{\mathbf{a}}$ increased to $1.19 \mu \mathrm{m}$ after the S1 samples were AWJP processed by ceramic balls with a pressure of $200 \mathrm{MPa}$, as shown in Figure $5 \mathrm{~b}$. In this process of AWJP, a great amount of small ceramic balls impacted the surface with high kinetic energy. The humps and horns on the surface are clearly visible, which means that the AWJP treatments by ceramic balls induce a large plastic deformation, and at the same time remove a part of the surface metal. 


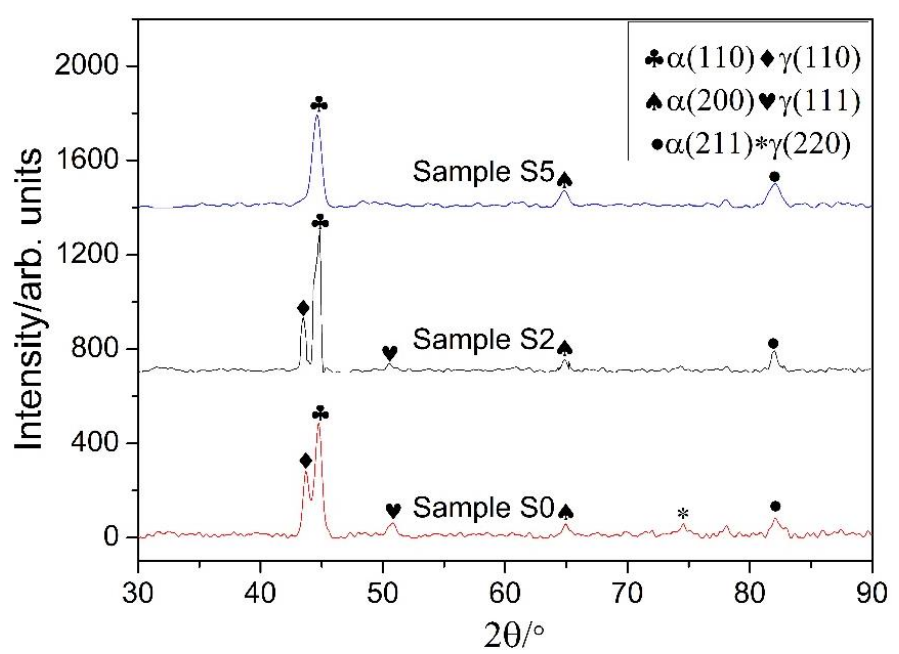

Figure 4. Surface X-ray diffraction (XRD) patterns of 18CrNiMo7-6 steel before and after AWJP.
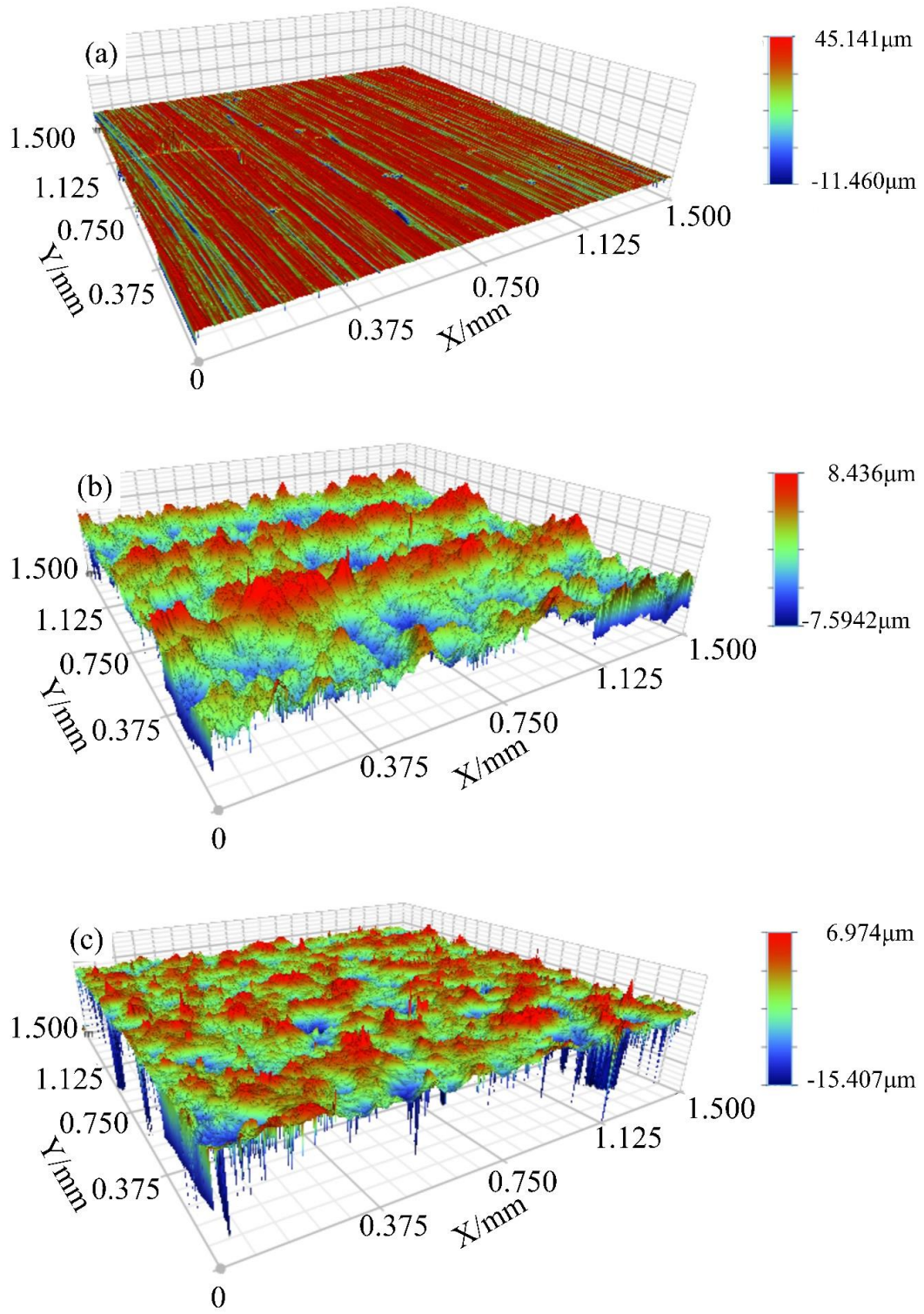

Figure 5. Cont. 

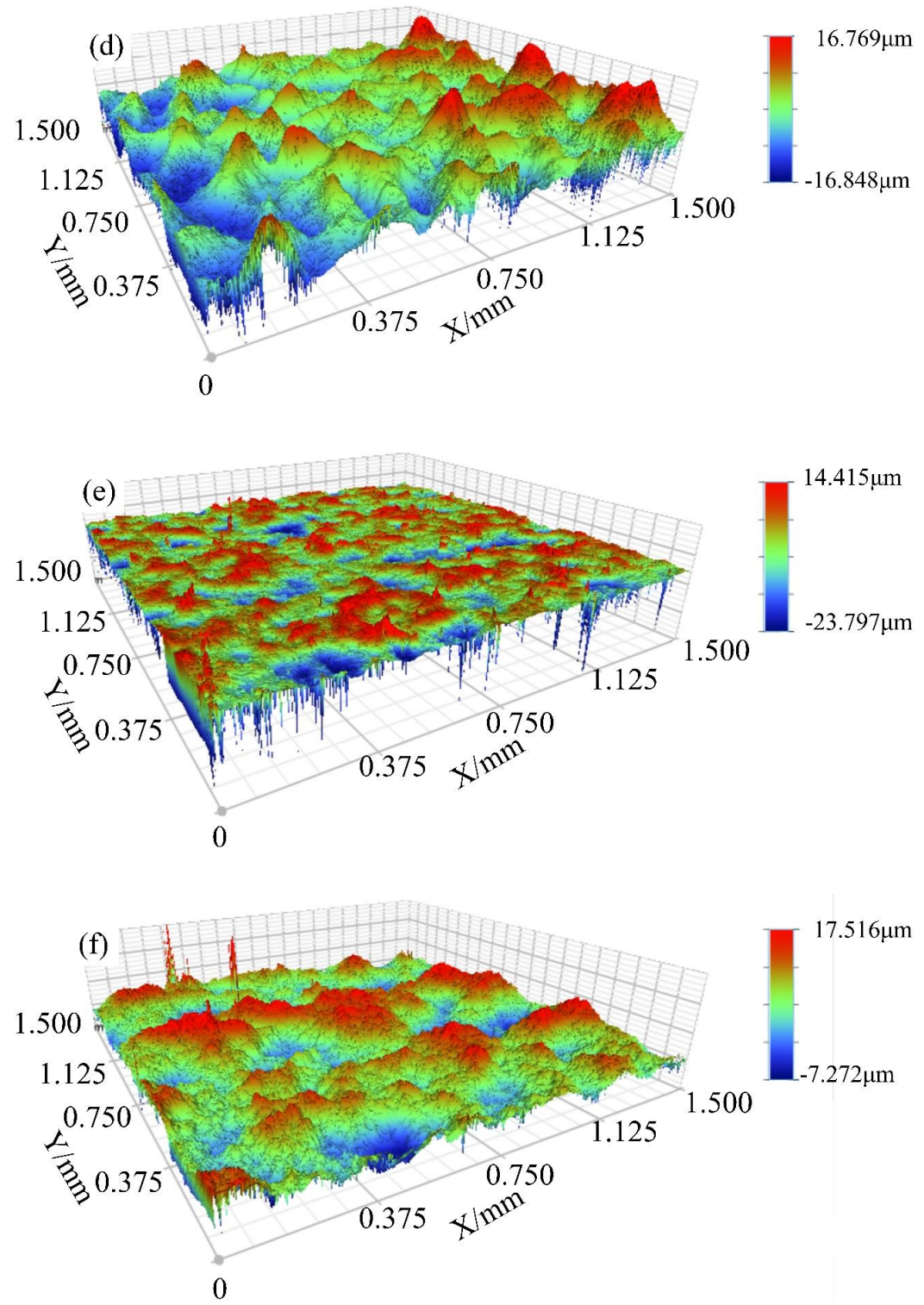

Figure 5. Surface topographies of samples before and after AWJP treatment: (a) Sample S0; (b) Sample S1; (c) Sample S2; (d) Sample S3; (e) Sample S4; and (f) Sample S5.

Table 5. Values of the surface roughness parameter of all samples.

\begin{tabular}{ccccccc}
\hline Variant & S0 & S1 & S2 & S3 & S4 & S5 \\
\hline $\mathrm{S}_{\mathbf{a}}(\mu \mathrm{m})$ & 0.19 & 1.19 & 0.66 & 2.96 & 0.69 & 1.64 \\
\hline
\end{tabular}

In contrast, if the AWJP process is conducted by cast steel balls $(0.2 \mathrm{~mm}$ round) with a pressure of $200 \mathrm{MPa}$, the surface roughness of the S2 sample is increased to $0.66 \mu \mathrm{m}$. This is because the use of larger and heavier cast steel balls can produce a higher level of plastic deformation, which will produce an arithmetic mean distributed texture, as shown in Figure 5c.

In Figure $5 d$, a lot of pits remain on the surface of the sample S3 treated by AWJP. The pits are due to the small indentations, and will lead to stress concentrations on the surface of the part, so we should eliminate the pits on the surface. The surface roughness of the S3 sample is increased to 2.96 $\mu \mathrm{m}$, which is approximated to be $383 \%$ more than that of the S2 sample. Therefore, the state of sample surface is apt to deteriorate, with the increase in the water pressure from $200 \mathrm{MPa}$ to $300 \mathrm{MPa}$. In order 
to decrease the surface roughness, the multiple AWJP processes were carried out on the surface of the samples S4 and S5.

As can be seen in Figure 5e,f, the surface roughness of sample S4 and S5 decrease to 0.69 and $1.64 \mu \mathrm{m}$, compared with sample S3 after the multiple AWJP processes. The humps on the surface of the sample are removed, and therefore the surface quality is improved after multiple AWJP.

\subsection{Hardness}

Figure 6 shows the hardness profiles of the samples treated under different AWJP processes. For sample S0, the maximum hardness appears on the surface, and then decreases with increasing depth and reaches a constant. However, after the samples are treated by the AWJP, all the samples are found to have a similar trend of hardness; the top surface hardness first increases to a maximum value, then decreases gradually along the depth of the layer, and finally remains constant. The sample S1 is treated by the ceramic balls peening with a water pressure of $200 \mathrm{MPa}$, and the thickness of its hardened layer is small compared to the others processed by the steel balls. This is to be expected, since because the ceramic balls have a lower impact kinetic energy than steel balls, the depth of the surface work hardening layer is small. The diversification trends of hardness are the same as those of residual stress, which is due to the relevance between the two factors. It was found that the hardness decreases with tensile residual stress, and increases with compressive residual stress [28].

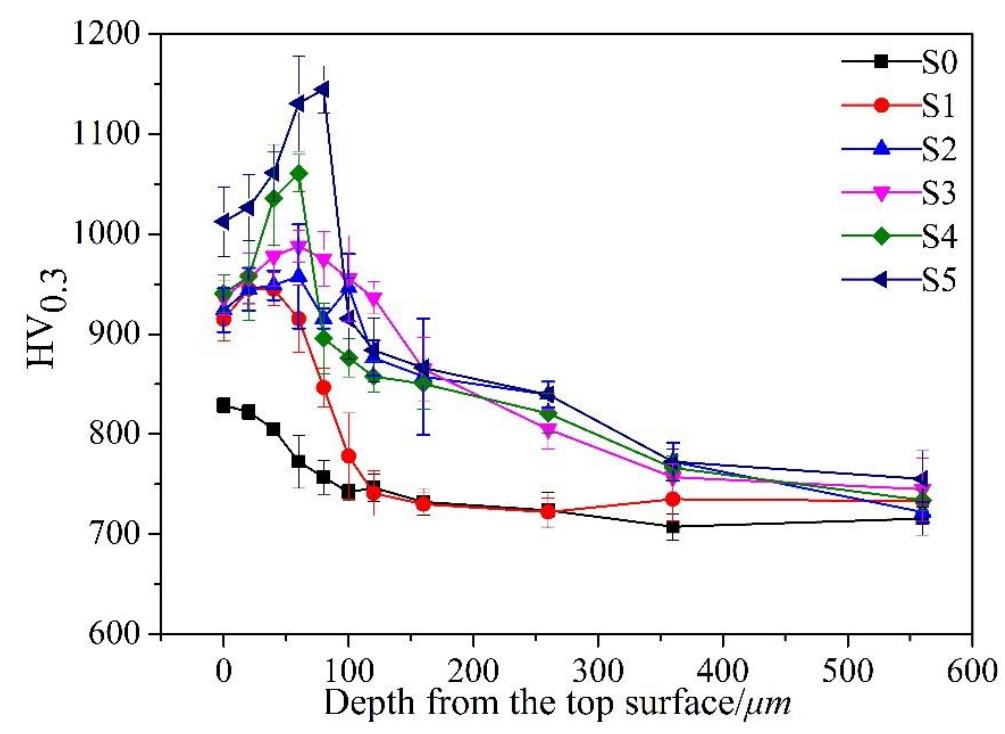

Figure 6. Microhardness as a function of the depth from the surface.

The average maximum hardness of the sample S5 increases up to a maximum of $1145 \mathrm{HV}_{0.3}$ at $80 \mu \mathrm{m}$. The results show that multiple AWJP increase the maximum hardness of sample S5 up by $15.9 \%$, compared to the maximum hardness of sample S3 $\left(988 \mathrm{HV}_{0.3}\right)$ treated by a single AWJP. Though the maximum hardness of samples treated by steel balls are different, the depth of hardened layers is almost the same. It is evident that the depth of the hardening layer depends on the first AWJP, rather than the following steps of the AWJP. The experimental results demonstrate that multiple AWJP can produce a larger work hardening layer in the $18 \mathrm{CrNiMo}-6$ steel than a single AWJP.

\subsection{Microstructure}

In Figure 7, the cross-sectional microstructures of sample S2 treated by AWJP are shown. Firstly, the cross-sectional microstructure of the sample S2 displays a typical carburized steel. The case-hardened zone consists of an almost martensite microstructure with a very small quantity of retained austenite and finely dispersed undissolved spherical carbide particles [5]. Secondly, it can be found that the plastic deformation layer is built on the surface of sample S2. Comparing Figure 7b with Figure 7c, 
the plastic deformation-induced grain refinement occurs during the AWJP treatment. The AWJP process projects balls along with high-pressure and high-speed water by the action of an external stress. When the external stress exceeds the critical stress for forming the deformation twins and the gain deformation, the grain refinement will be induced by plastic deformation [29].

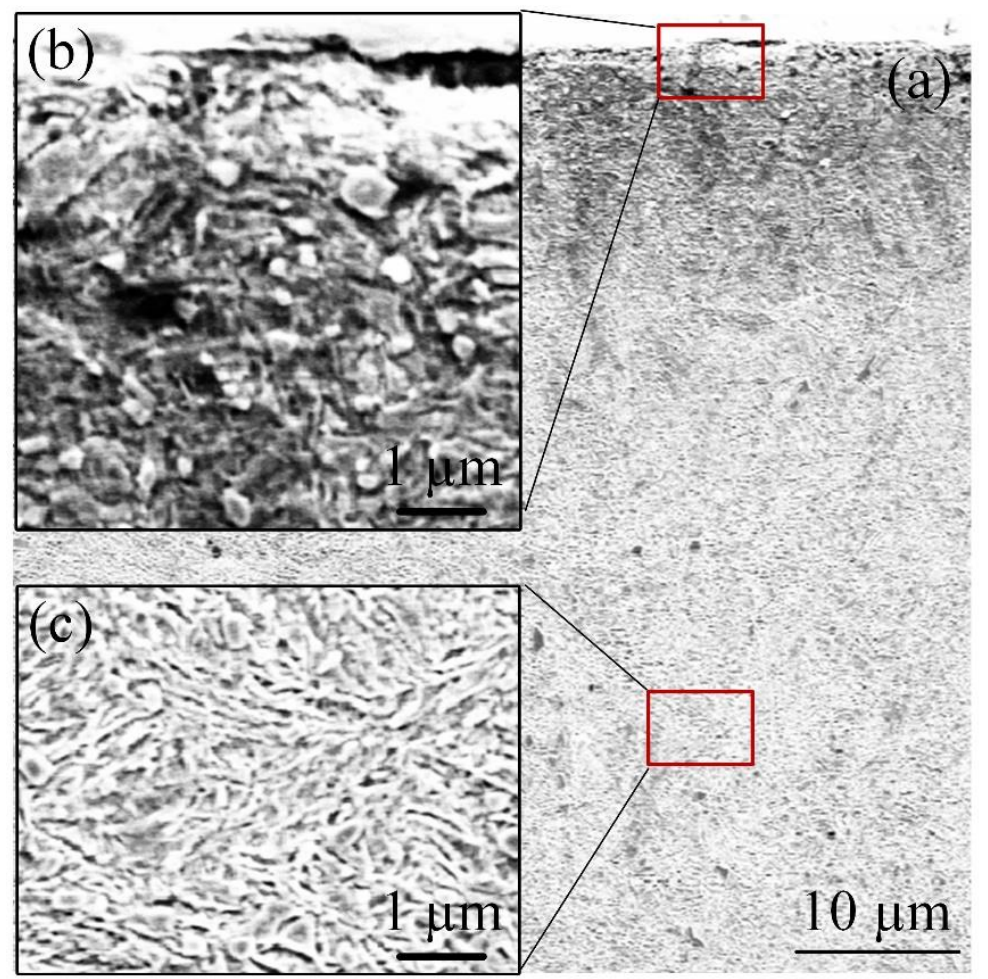

Figure 7. Cross-sectional microstructures of sample S2 after AWJP treatment.

\section{Conclusions}

In summary, after multiple AWJP treatments were implemented to $18 \mathrm{CrNiMo7}-6$ steel, the uniformity of the residual stress distribution was studied by XRD. The results showed that the specimens after triple AWJP treatments had a high compressive residual stress of $-1455 \mathrm{MPa}$ and a small standard deviation of $22.05 \mathrm{MPa}$. It is indicated that the multiple AWJP treatments can improve the uniformity of distribution and the values of residual stress. In addition, the multiple AWJP treatments reduced the surface roughness following the single AWJP. The hardness was improved to $1145 \mathrm{HV}_{0.3}$, which has the same trend with the residual stress. The AWJP by steel balls produced a thicker hardening layer, with higher hardness than the AWJP by ceramic balls. These results confirm that multiple AWJP is a more effective surface treatment than single AWJP. These results can provide a basic experimental foundation for improving the fatigue strength and wear resistance of 18CrNiMo7-6 steel.

Author Contributions: Conceptualization, Y.L.; methodology, Y.L.; software, D.W.; validation, Y.X.; writing-original draft preparation, Y.Z. and J.L.; writing-review and editing, Y.Z. and S.L.; and funding acquisition, Y.L. All authors have read and agreed to the published version of the manuscript.

Funding: This research was funded by the National Science Foundation of China under Grant 51705470, and 51801185, and U1804254; Key Research Project of the Higher Education Institutions of Henan Province, Henan Provincial Department of Education, China, under Grant 18A460032 and 19A460007; Special Research and Promotion Project of Henan Province, China, under Grant 182102210009.

Conflicts of Interest: The authors declare no conflict of interest. 


\section{References}

1. Smith, D.; Joris, O.P.J.; Sankaran, A.; Weekes, H.E.; Bull, D.J.; Prior, T.J.; Dye, D.; Errandonea, D.; Proctor, J.E. On the high-pressure phase stability and elastic properties of $\beta$-titanium alloys. J. Phys. Condens. Matter 2017, 29, 1-7. [CrossRef] [PubMed]

2. Grajcar, A.; Morawiec, M.; Zalecki, W. Austenite Decomposition and Precipitation Behavior of Plastically Deformed Low-Si Microalloyed Steel. Metals 2018, 8, 1028. [CrossRef]

3. Mandal, P.; Olasolo, M.; Silva, L.D.; Lalvani, H. Impact of a Multi-Step Heat Treatment on Different Manufacturing Routes of 18crnimo7-6 Steel. Met. Mater. Trans. A 2020, 51, 3009-3029. [CrossRef]

4. Wagner, L. Mechanical Surface Treatments on Titanium, Aluminum and Magnesium Alloys. Mater. Sci. Eng. A Struct. Mater. Prop. Microstruct. Process. 1999, 263, 210-216. [CrossRef]

5. Ho, H.S.; Li, D.L.; Zhang, E.L.; Niu, P.H. Shot Peening Effects on Subsurface Layer Properties and Fatigue Performance of Case-Hardened 18crnimo7-6 Steel. Adv. Mater. Sci. Eng. 2018, 2018, 3795798. [CrossRef]

6. Soyama, H. Comparison between Shot Peening, Cavitation Peening, and Laser Peening by Observation of Crack Initiation and Crack Growth in Stainless Steel. Metals 2010, 10, 63-80. [CrossRef]

7. Lu, Y.; Sun, G.F.; Wang, Z.D.; Su, B.Y.; Zhang, Y.K.; Ni, Z.H. The Effects of Laser Peening on Laser Additive Manufactured 3161 Steel. Int. J. Adv. Manuf. Technol. 2020, 107, 2239-2249. [CrossRef]

8. Langer, K.; Spradlin, T.J.; Fitzpatrick, M.E. Finite Element Analysis of Laser Peening of Thin Aluminum Structures. Metals 2020, 10, 93. [CrossRef]

9. Tao, N.R.; Lu, K. Preparation Techniques for Nano Structured Metallic Materials via Plastic Deformation. Acta Met. Sin. 2014, 5, 141-147. [CrossRef]

10. Li, W.L.; Tao, N.R.; Lu, K. Fabrication of a Gradient Nano-Micro-Structured Surface Layer on Bulk Copper by Means of a Surface Mechanical Grinding Treatment. Scr. Mater. 2008, 59, 546-549. [CrossRef]

11. Huang, H.W.; Wang, Z.B.; Liu, L.; Yong, X.P.; Lu, K. Formation of a Gradient Nanostructured Surface Layer on a Martensitic Stainless Steel and Its Effects on the Electrochemical Corrosion Behavior. Acta Met. Sin. 2015, 51, 513-518. [CrossRef]

12. Tao, N.R.; Wang, Z.B.; Tong, W.P.; Sui, M.L.; Lu, J.; Lu, K. An Investigation of Surface Nanocrystallization Mechanism in Fe Induced by Surface Mechanical Attrition Treatment. Acta Mater. 2020, 50, 4603-4616. [CrossRef]

13. Li, X.Y.; Lu, K. Playing with Defects in Metals. Nat. Mater. 2017, 16, 700-701. [CrossRef] [PubMed]

14. Fu, H.; Liang, Y.L. Study of the Surface Integrity and High Cycle Fatigue Performance of Aisi 4340 Steel after Composite Surface Modification. Metals 2019, 9, 856. [CrossRef]

15. Zhang, M.; He, Z.S.; Zhang, Y.X.; Wang, X.D.; Zhao, S.S.; Fu, T.; Chen, L. Theoretical and Finite Element Analysis of Residual Stress Field for Different Geometrical Features after Abrasive Waterjet Peening. J. Press. Vessel Technol. Trans. ASME 2018, 141, 11401-11412. [CrossRef]

16. Arola, D.; Alade, A.E.; Weber, W. Improving Fatigue Strength of Metals Using Abrasive Waterjet Peening. Mach. Sci. Tech. 2006, 10, 197-218. [CrossRef]

17. Arola, D.; McCain, M.L.; Kunaporn, S.; Ramulu, M. Waterjet and Abrasive Waterjet Surface Treatment of Titanium: A Comparison of Surface Texture and Residual Stress. Wear 2001, 249, 943-950. [CrossRef]

18. Sadasivam, B.; Arola, D. Finite Element Based Evaluation of Abrasive Waterjet Peening with Elastic Prestress: Effect of Prestress Loading. Int. Mech. Eng. Congr. Expo. 2013, 3, 2091-2096. [CrossRef]

19. Chen, M.; Liu, H.B.; Wang, L.B.; Wang, C.X.; Zhu, K.Y.; Xu, Z.; Jiang, C.H.; Ji, V. Evaluation of the Residual Stress and Microstructure Character in Saf 2507 Duplex Stainless Steel after Multiple Shot Peening Process. Surf. Coat. Technol. 2018, 344, 132-140. [CrossRef]

20. Feng, Q.; She, J.; Wu, X.Y.; Wang, C.X.; Jiang, C.H. The Effect of Multiple Shot Peening on the Corrosion Behavior of Duplex Stainless Steel. J. Mater. Eng. Perform. 2018, 27, 1396-1403. [CrossRef]

21. Fu, P.; Jiang, C.H.; Ji, V. Microstructural Evolution and Mechanical Response of the Surface of 18crnimo7-6 Steel after Multistep Shot Peening during Annealing. Mater. Trans. 2013, 54, 2180-2184. [CrossRef]

22. Fu, P.; Zhan, K.; Jiang, C.H. Micro-Structure and Surface Layer Properties of 18crnimo7-6 Steel after Multistep Shot Peening. Mater. Des. 2013, 51, 309-314. [CrossRef]

23. Zhan, K.; Jiang, C.H.; Ji, V. Uniformity of Residual Stress Distribution on the Surface of S30432 Austenitic Stainless Steel by Different Shot Peening Processes. Mater. Lett. 2013, 99, 61-64. [CrossRef] 
24. Zou, Y.; Sang, Z.K.; Wang, Q.L.; Li, T.C.; Li, D.L.; Li, Y. Improving the Mechanical Properties of 304 Stainless Steel Using Waterjet Peening. Mater. Sci. Med. 2020, 26, 161-167. [CrossRef]

25. Noyan, I.C.; Cohen, J.B. Residual Stress Measurement by Diffraction and Interpretation; Springer: New York, NY, USA, 1987. [CrossRef]

26. Mohamed, A.M.O.; Farhat, Z.; Warkentin, A.; Gillis, J. Effect of a Moving Automated Shot Peening and Peening Parameters on Surface Integrity of Low Carbon Steel. J. Mater. Proc. Technol. 2020, 277, 116399. [CrossRef]

27. Kobayashi, M.; Matsui, T.; Murakami, Y. Mechanism of Creation of Compressive Residual Stress by Shot Peening. Int. J. Fatigue 1998, 20, 351-357. [CrossRef]

28. Huber, N.; Heerens, J. On the effect of a general residual stress state on indentation and hardness testing. Acta Mater. 2008, 56, 6205-6213. [CrossRef]

29. An, X.H.; Lin, Q.Y.; Wu, S.D.; Zhang, Z.F. Improved fatigue strengths of nanocrystalline $\mathrm{Cu}$ and $\mathrm{Cu}-\mathrm{Al}$ alloys. Mater. Res. Lett. 2015, 3, 135-141. [CrossRef]

(C) 2020 by the authors. Licensee MDPI, Basel, Switzerland. This article is an open access article distributed under the terms and conditions of the Creative Commons Attribution (CC BY) license (http://creativecommons.org/licenses/by/4.0/). 